\title{
The feasibility of using biopsy samples from esophageal cancer for comprehensive gene expression profiling
}

\author{
MASAAKI MOTOORI ${ }^{1,2}$, ICHIRO TAKEMASA ${ }^{1}$, MAKOTO YAMASAKI ${ }^{1}$, \\ TAKAMICHI KOMORI ${ }^{1}$, ATSUSHI TAKENO ${ }^{1}$, HIROSHI MIYATA ${ }^{1}$, SHUJI TAKIGUCHI $^{1}$, \\ YOSHIYUKI FUJIWARA ${ }^{1}$, TAKUSHI YASUDA ${ }^{1}$, MASAHIKO YANO ${ }^{2}$, NARIAKI MATSUURA ${ }^{3}$, \\ KENICHI MATSUBARA ${ }^{4}$, MORITO MONDEN $^{1}$, MASAKI MORI $^{1}$ and YUICHIRO DOKI $^{1}$
${ }^{1}$ Department of Gastroenterological Surgery, Graduate School of Medicine, Osaka University, 2-2 Yamadaoka Suita, Osaka 565-0871; ${ }^{2}$ Department of Surgery, Osaka Medical Center for Cancer and Cardiovascular Diseases, 1-3-3 Nakamichi, Higashinari-ku, Osaka 537-8511; ${ }^{3}$ Department of Functional Diagnostic Science, Graduate School of Medicine, Osaka University, 2-2 Yamadaoka, Suita, Osaka 565-0871; ${ }^{4}$ DNA Chip Research Inc., 1-1-43 Suehiro, Tsurumi, Yokohama, Kanagawa 230-0045, Japan

Received January 22, 2009; Accepted March 30, 2009

DOI: 10.3892/ijo_00000336

\begin{abstract}
Advanced esophageal cancer has been recently treated by multimodal therapy including preoperative chemotherapy or chemoradiotherapy and surgery. A biopsy sample provides a valuable specimen for understanding the biological characteristics of individual esophageal cancer. Pretreatment prediction of the response to chemotherapy or radiotherapy based on biological characteristics using biopsy samples is a desirable goal. In using biopsy samples for molecular analysis, there are two problems; the proportion of cancer cells and the intratumor heterogeneity. This study was conducted to investigate the feasibility of using endoscopic biopsy samples of esophageal squamous cell cancer (ESCC) for comprehensive gene expression profiling (GEP). Comprehensive GEP was performed in 40 bulky ESCC specimens and 10 normal esophageal epithelial specimens from patients who underwent esophageal resection and 52 endoscopic ESCC biopsy samples from 26 patients (two samples per one patient). Unsupervised hierarchical cluster analysis showed distinct profiles between the bulky ESCC specimens and normal epithelial specimens. Also, unsupervised hierarchical cluster analysis revealed distinct profiles between the biopsy ESCC samples and normal epithelial specimens. Moreover, a couple of biopsy samples taken from different locations of the same tumor were closely clustered together. That is, biopsy ESCC samples were distinguished from normal esophageal epithelial specimens and the intratumor heterogeneity of GEP was smaller than
\end{abstract}

Correspondence to: Dr Ichiro Takemasa, Department of Gastroenterological Surgery, Graduate School of Medicine, Osaka University, 2-2 Yamadaoka Suita, Osaka 565-0871, Japan E-mail: alfa-t@sf6.so-net.ne.jp

Key words: esophageal cancer, endoscopic biopsy sample, gene expression profiling, intratumor heterogeneity intertumor heterogeneity. GEP using biopsy ESCC samples is feasible and has the potential to represent the biological properties.

\section{Introduction}

Advanced esophageal cancer, which has a poor prognosis, has been previously treated by multimodal therapy including preoperative chemotherapy or chemoradio therapy and surgery $(1,2)$. Neoadjuvant therapy has been shown to improve the prognosis of responders. On the other hand, non-responders not only suffer from side effects but also lose precious time to take advantage of other possible treatments $(3,4)$. Therefore, pretreatment prediction of the response to chemoor radiotherapy is one of the most desirable goals in clinical practice, but pretreatment clinocopathological factors are unable to predict the response and there is no reliable method. Biological characteristics of a tumor are important factors affecting the malignant potential and sensitivity to chemotherapy or radiotherapy.

A pretreatment biopsy sample provides a valuable specimen for understanding the biological characteristics of individual esophageal cancer. Molecular analyses, such as RT-PCR and immunohistochemistry, of pretreatment endoscopic biopsy samples of esophageal cancer have been performed to understand the biological characteristics of esophageal cancer (5-7). However, only one gene or a few genes have been addressed in these studies. Multiple genetic alterations are involved in the development and progression of esophageal cancer and these aberrations may affect the expression of a large number of genes $(8,9)$ and numerous molecular pathways may contribute to the sensitivity of chemotherapy or radiotherapy. Gene expression profiling (GEP) allows assessment of expression of thousands of genes simultaneously and is one of the powerful tools for understanding the biological characteristics of each tumor. In fact, this approach has already been used to identify genes that could serve as molecular markers of cancer classification and 
outcome prediction (10-14). In esophageal cancer, GEP using surgical resection samples has been performed (15-17). However, these results can be used only in the selection of post operative adjuvant therapy or follow-up schedules. To apply the results of GEP to therapeutic planning of esophageal cancer in clinical practice, pretreatment endoscopic biopsy samples should be analyzed. Recently, GEP using not only surgically resection samples but also biopsy samples has been successfully performed (18-21).

Endoscopic biopsy samples are usually small and morphologically esophageal cancer often displays intratumor macroscopic and microscopic heterogeneity. If the biopsy samples used for molecular analysis contain no or few cancer cells, it would not represent the biological characteristics of a tumor. If the gene expression of samples taken from different locations in the same tumor is drastically different, biological classification based on molecular analysis of biopsy samples may not be suitable. That is, in using biopsy samples for molecular analysis, there are two problems; the proportion of cancer cells and the intratumor heterogeneity of gene expression. However, there have been few studies addressing these problems (7).

This study investigated whether biopsy ESCC samples can be distinguished from normal esophageal epithelial specimens by GEP and assessed the intratumor heterogeneity of GEP by analyzing a couple of biopsy samples taken from different locations of the same tumor.

\section{Materials and methods}

Patients and clinical samples. Esophageal squamous cell cancer (ESCC) samples were obtained from 40 patients and normal esophageal epithelial specimens from 10 patients who underwent a surgical resection. The clinicopathological characteristics of the resected ESCC specimens are listed in Table I. Normal esophageal epithelial specimens were collected from the area normally stained by the Lugol dye. In addition, a couple of endoscopic biopsy samples of ESCC were obtained from 26 patients and assayed separately (Fig. 1). The clinicopathological characteristics of the biopsy ESCC specimens are listed in Table II. None of the patients received either chemotherapy or radiotherapy before the surgery or endoscopy. Tissue specimens were disrupted in RNAlater (Ambion, Austin, TX) and stored at $4^{\circ} \mathrm{C}$ for $1-2 \mathrm{~h}$, then at $-80^{\circ} \mathrm{C}$ until use. For each biopsy specimen, an adjacent cancer tissue biopsy was given to a pathologist for assessing the presence of cancer and its histology. Routine hematoxylin and eosin- (H\&E) stained slides were used. All aspects of this study protocol were performed according to the ethical guidelines set by the committee of the three Ministries of the Japanese Government and a signed consent form was obtained from each subject.

Cellular composition of the biopsy specimens. The cellular composition of biopsy specimens was determined by an evaluation of the cell squares in the H\&E-stained slides using light microscopy. These results were recorded as percentages. A total 110 biopsy samples from 45 ESCC patients, partly including patients enrolled in the microarray analysis, were analyzed.
Table I. The clinicopathological characteristics of the resection ESCC specimens.

Characteristics

No. of patients

\section{Gender}

Male/Female

030/10

Age

Median

Tumor location ${ }^{\mathrm{a}}$

Cervical esophagus

Upper thoracic esophagus

Middle thoracic esophagus

Lower thoracic esophagus

Pathological T category ${ }^{\mathrm{a}}$

pT1

pT2

pT3

pT4

Pathological N category ${ }^{\mathrm{a}}$

pNO

$\mathrm{pN} 1$

pM1(LYM)

Pathological disease stage

pStage I

pStage II

11

pStage III

13

pStage IV

14

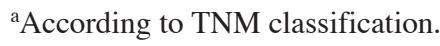

Extraction and quality assessment of RNA. Total RNA was purified from clinical samples utilizing TRIzol reagent (Invitrogen, San Diego, CA) as described in the accompanying protocol. The integrity of RNA was assessed by Agilent 2100 Bioanalyzer and RNA 6000 LabChip kits (Yokokawa Analytical Systems, Tokyo, Japan). Only high-quality RNA with intact $18 \mathrm{~S}$ and $28 \mathrm{~S}$ ribosomal RNA was used for the subsequent analysis. For control reference, 15 RNA samples from normal esophageal epithelial specimens were mixed.

Preparation of fluorescent-labeled aRNA targets and hybridization. The extracted RNA samples were amplified with T7 RNA polymerase using Amino Allyl MessageAmp ${ }^{\text {TM }}$ aRNA kit (Ambion) according to the manufacturer's protocol. The quality of each Amino Allyl-aRNA sample was checked by Agilent 2100 Bioanalyzer. Five $\mu \mathrm{g}$ of control and experimental aRNA samples were labeled with $\mathrm{Cy} 3$ and Cy5, respectively, mixed and hybridized on an oligonucleotide microarray covering 30,000 human probes (AceGene Human 30K; DNA Chip Research Inc. and Hitachi Software Engineering Co., Ltd., Yokohama Japan). The experimental protocol is available at http://www.dnachip.co.jp/thesis/AceGeneProtocol.pdf. Thereafter, the microarrays were scanned using the ScanArray 4000 (GSI Lumonics, Billerica, MA). 


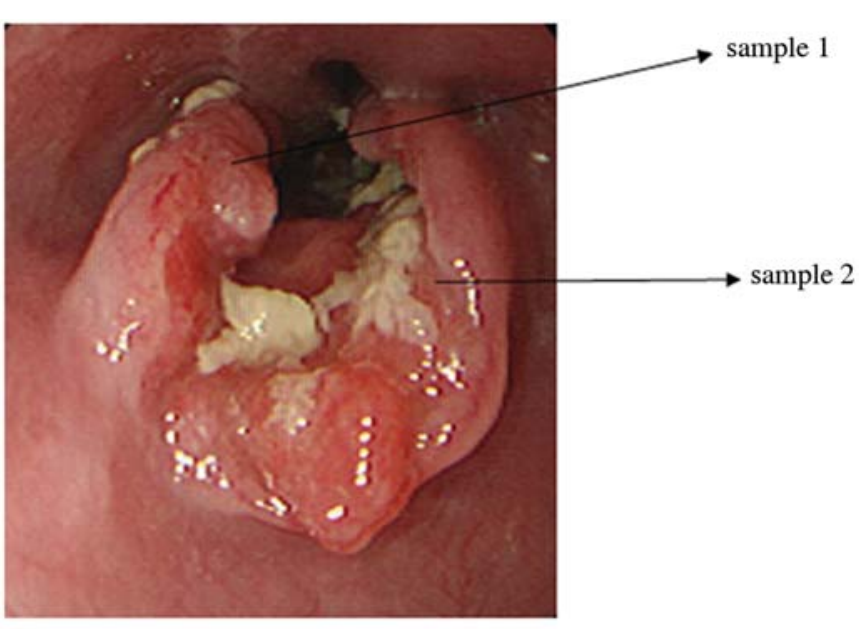

Figure 1. Sampling method for the biopsy ESCC specimens. A couple of biopsy samples were collected from each patient during a routine endoscopic examination.

Table II. The clinicopathological characteristics of the biopsy ESCC specimens.

Characteristics No. of patients

\section{Gender}

Male/Female

Age

Median

Tumor location ${ }^{\mathrm{a}}$

Upper thoracic esophagus

Middle thoracic esophagus

Lower thoracic esophagus

Pretherapeutic clinical T category ${ }^{\mathrm{a}}$

cT1

cT2

cT3

cT4

Pretherapeutic clinical N category ${ }^{\mathrm{a}}$

cNO

$\mathrm{cN} 1$

cM1(LYM)

Pretherapeutic clinical stage ${ }^{a}$

cStage I

cStage II

cStage III

cStage IV performed by subtracting a median of all $\log (\mathrm{Cy} 5 / \mathrm{Cy} 3)$ values from each $\log (\mathrm{Cy} 5 / \mathrm{Cy} 3)$ value. Genes with missing values in $>10 \%$ of the samples were excluded from further analysis. Hierarchical cluster analysis (HCA) with Euclidean distance as a similarity coefficient and Ward as a clustering algorithm was performed using GeneMath 2.0 software (Applied Maths, Inc., Austin, TX).

Up-or down-regulated genes. Commonly up-regulated genes were defined when their expression levels were 2-fold or more against the control reference in at least $50 \%$ of the samples. In addition, commonly down-regulated genes were defined when their expression levels were half-fold or less against the control reference in at least $50 \%$ of the samples.

$R T$-PCR. To verify our microarray data, RT-PCR was performed for two of the commonly up-regulated genes $(M M P 9$ and $S P A R C)$. Total RNA ( $2 \mu \mathrm{g})$ from eight biopsy ESCC specimens and control reference (mixture of fifteen RNAs from normal esophageal epithelial specimens) was used for the reverse-transcription reaction with oligo-(dT) primer, using the Reverse Transcription System (Promega, Madison, WI). PCR was performed in a $25 \mu 1$ reaction mixture containing $1 \mu \mathrm{l}$ of cDNA template, $0.2 \mathrm{mmol} / \mathrm{l}$ of each primer and 1 unit of Taq DNA Polymerase (AmpliTaq Gold, Roche Molecular Systems, Pleasanton, CA), as follows; one cycle of $95^{\circ} \mathrm{C}$ for $12 \mathrm{~min}$, followed by 25 cycles of $94^{\circ} \mathrm{C}$ for $1 \mathrm{~min}$, $60^{\circ} \mathrm{C}$ for $1 \mathrm{~min}, 72^{\circ} \mathrm{C}$ for $1.5 \mathrm{~min}$, followed by $72^{\circ} \mathrm{C}$ for $10 \mathrm{~min}$. The primers were designed by using Web-based Primer 3 software (http://frodo.wi.mit.edu/cgi-bin/primer3/primer3_ www.cgi). GAPDH was also amplified as a marker to confirm the amounts of cDNA generated from each sample. PCR products were visualized with ethidium bromide following separation by electrophoresis on $2 \%$ agarose gel.

\section{Results}

Cellular composition of biopsy specimens. The mean percentage of tumor cells and stromal cells were 46 and $26 \%$ with a standard deviation of 20 and 16, respectively.

Total RNA yield from biopsy specimens. The average and minimum volume of total RNA from one biopsy sample was 17.7 and $2.2 \mu \mathrm{g}$, respectively. The quality of all the extracted RNAs was sufficient for comprehensive GEP with intact $18 \mathrm{~S}$ and $28 \mathrm{~S}$ ribosomal RNA.

Gene expression profiling between resection ESCC specimens and normal esophageal epithelial specimens and between biopsy ESCC specimens and normal esophageal epithelial specimens. First, GEP was compared between resection ESCC specimens and normal esophageal epithelial specimens. After gene processing described previously, 18,718 genes were used for further analysis. Unsupervised HCA using all 18,718 genes showed distinct profiles between the two groups (Fig. 2). All resection ESCC specimens were distinguished from normal esophageal epithelial specimens by GEP.

Secondly, GEP was compared between biopsy ESCC specimens and normal esophageal epithelial specimens. After gene processing, 18,734 genes were used for further analysis.
Analysis of microarray data. Signal values were calculated by DNASISArray software (Hitachi Software Inc. Tokyo, Japan). Following background subtraction, data with low signal intensities were excluded from additional investigation In each sample, the $\mathrm{Cy} 5 / \mathrm{Cy} 3$ ratio values were log-transformed and global equalization to remove a deviation of the signal intensity between whole Cy3- and Cy5-fluorescence was 


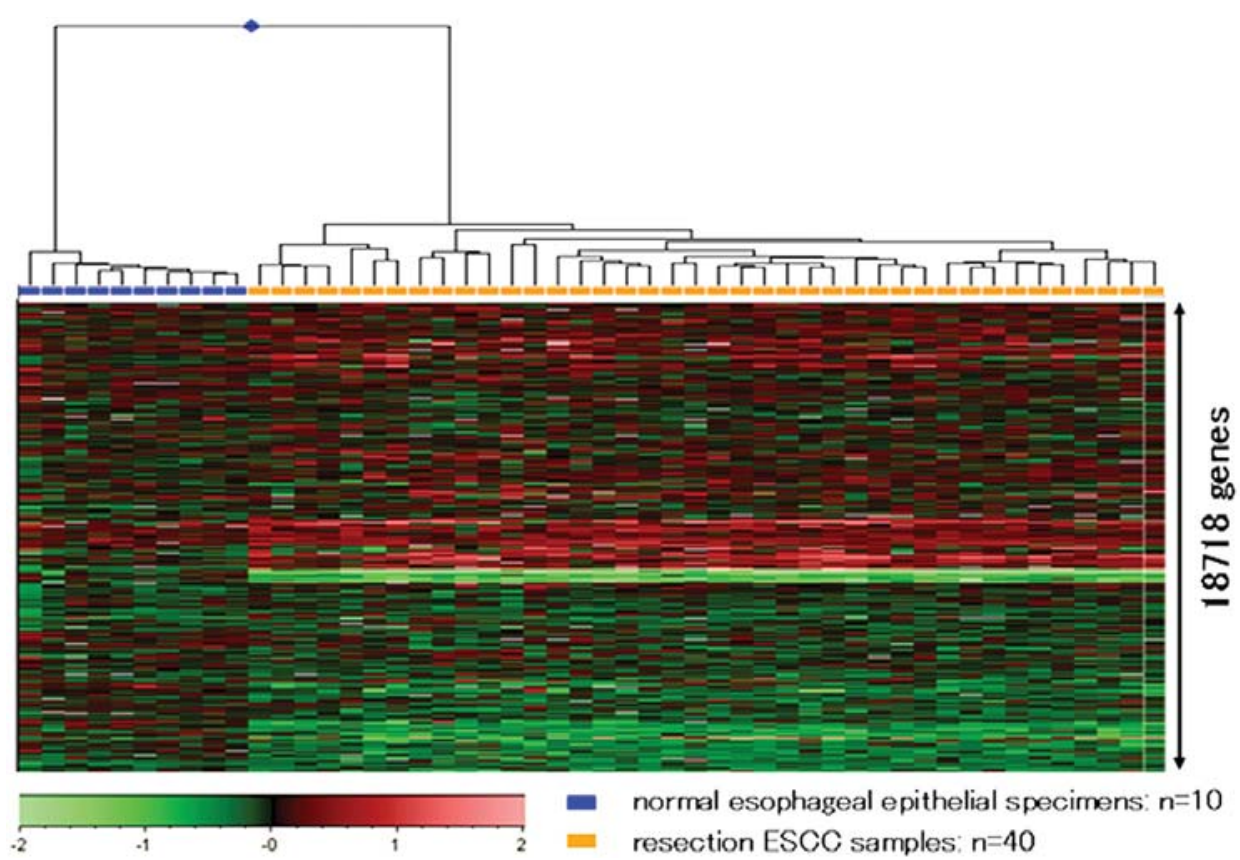

Figure 2. Hierarchical cluster analysis with 18,718 genes in 40 resection ESCC samples and 10 normal esophageal epithelial specimens. The rows and columns represent genes and samples, respectively. The color scale at the bottom indicates the relative expression levels in terms of standard deviations from the median.

Unsupervised HCA using all 18,734 genes showed distinct profiles between the two groups (Fig. 3). Almost all biopsy ESCC specimens except one specimen were distinguished from normal esophageal epithelial specimens by GEP. Moreover, a couple of biopsy samples taken from different locations of the same tumor were closely clustered together, except one case.

Commonly up-or down-regulated genes in resection and biopsy ESCC specimens. A total of 129 and 136 commonly up-regulated genes were identified in the resection and biopsy ESCC specimens, respectively and 85 genes ( 65\%) were overlapped in both groups. In addition, 518 and 506 commonly down-regulated genes were identified in resection and biopsy ESCC specimens, respectively and 444 genes $(\sim 85 \%)$ were overlapped in both groups. To confirm the microarray data, RT-PCR was performed for two of the commonly up-regulated genes (MMP9 and SPARC) in eight biopsy samples. These genes have been reported to be associated with progression of esophageal cancer $(22,23)$. The expression patterns of RT-PCR closely agreed with those of the microarray in both genes (Fig. 4).

\section{Discussion}

To understand the biological characteristics of individual esophageal cancer, molecular analysis of pretreatment endoscopic biopsy samples have been performed. Miyata et al performed immunohistochemical analysis of six molecules in pre radiation biopsy samples. The sensitivity of radiation therapy was significantly correlated with $p 53$ and $C D C 25 B$ expression (6). Langer et al investigated expression of 12 molecules in pretreatment biopsy samples using a real-time RT-PCR analysis and compared the histological effect to cisplatin and 5-fluorouracil chemotherapy. MTHFR, caldesmon and MRPl were significantly associated with the response (7). However, it is clear that several genes will not define the biological characteristics of individual tumors. The properties of each tumor are likely to reflect the functions of all gene products. Therefore, multiple markers will be needed to adequately define the sensitivity of tumors to chemotherapy or radiotherapy and GEP, which can assess the expression of thousands of genes, will likely to be a suitable approach. This is a feasibility study of using biopsy samples in comprehensive GEP for future clinical application.

Cancer tissues consist of mixed populations of cancer cells and stromal cells, such as fibroblasts, infiltrating lymphocytes and endothelial cells. GEP of cancer is currently based on two main methods of RNA preparation; whole tissue RNA extraction and laser capture microdissection (LCM). LCM certainly can improve tissue sampling and achieve homogeneity of the tumor tissue. However, stromal elements play multiple roles in tumor growth and progression and also contribute to tumor response to chemotherapy or radiotherapy (24-26). The biological characteristics of a tumor are considered to be reflected by both the cancer cells and stromal cells, so whole tissues of the specimens were analyzed.

Endoscopic ESCC biopsy samples are small, so it is very difficult to assess the proportion of cancer cells by investigating a part of a sample. In the H\&E-stained slides, the average ratio of cancer cells and stromal cells of biopsy specimens was 46 and $26 \%$, respectively, although these samples were different from those actually used in the microarray analysis. If the biopsy sample using comprehensive GEP is composed of mostly normal cells, it would not represent the biological characteristics of a tumor. First, this study confirmed that resection ESCC specimens were distinguished from normal esophageal epithelial specimens by GEP. Then, it verified that biopsy ESCC specimens were distinguished from normal esophageal epithelial specimens by GEP. In this study, the 

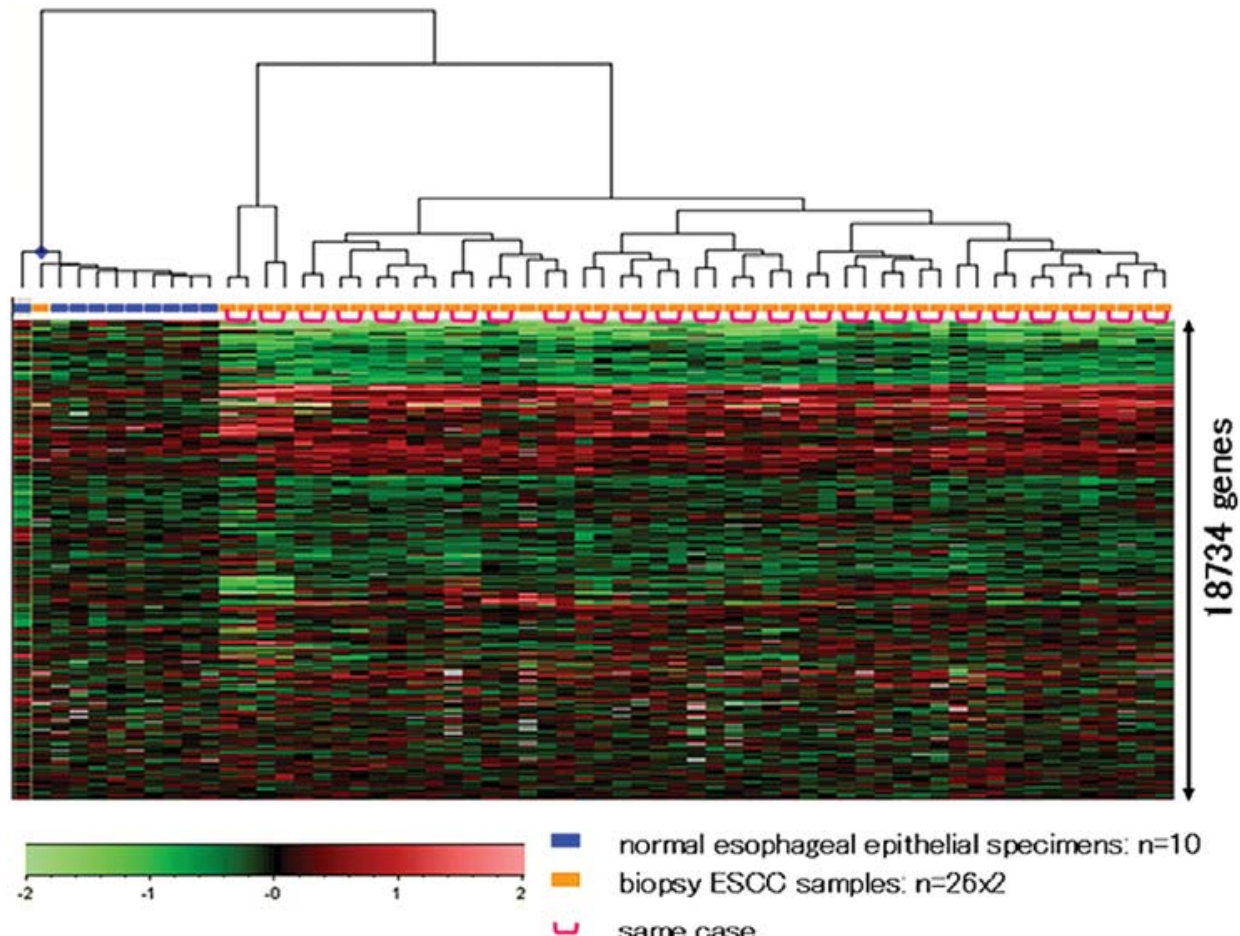

normal esophageal epithelial specimens: $\mathrm{n}=10$

biopsy ESCC samples: $n=26 \times 2$

ᄂ same case

Figure 3. Hierarchical cluster analysis with 18,734 genes in 52 biopsy ESCC samples and 10 normal esophageal epithelial specimens. The rows and columns represent genes and samples, respectively. The color scale at the bottom indicates the relative expression levels in terms of standard deviations from the median.

A

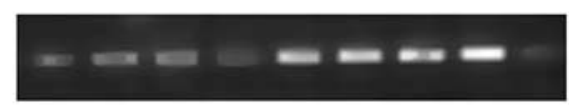

Sample

Expression levels In microarray

B

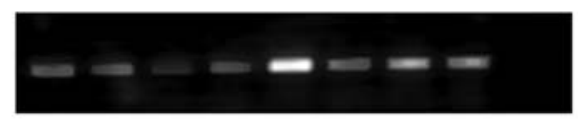

$\begin{array}{lllllllllll}\text { Sample } & \text { T1 } & \text { T2 } & \text { T3 } & \text { T4 } & \text { T5 } & \text { T6 } & \text { T7 } & \text { T8 } & \mathrm{N}\end{array}$

Expression levels In microarray

$\begin{array}{llllllll}2.2 & 2.7 & 1.6 & 3.8 & 4.5 & 1.8 & 3.2 & 2.8\end{array}$

Figure 4. The expression patterns of RT-PCR. (A) SPARC and (B) MMP9. T1-T8, biopsy cancer sample. N, control reference.

reason that one biopsy specimen could not be distinguished from the normal esophageal epithelial specimens, perhaps, was that there was a low proportion of cancer cells due to a sampling error, though it was possibly adequate for the diagnosis of cancer by microscopy.

There is histopathological heterogeneity in esophageal cancer, as in other solid tumors. The influence of such morphological intratumor heterogeneity on GEP is not clear, though the heterogeneity is detected in individual genes $(4,27,28)$. Therefore, the difference of GEP between biopsy samples taken from different locations in the same tumor should be elucidated. In the current study, a couple of endoscopic biopsy samples obtained from the same case were closely clustered together in almost all cases. This result means that the intratumor heterogeneity of GEP is smaller than intertumor heterogeneity in the superficial position of esophageal cancer and one biopsy specimen may represent GEP of the superficial position of esophageal cancer. Concerning the intratumor heterogeneity of GEP in other solid tumors, the degree of GEP variability within gastric cancer samples isolated from resection specimens of same patient was remarkably low (29). In surgically resected soft tissue sarcomas, the average intratumor distance was considerably shorter than the intertumor distance and intratumor heterogeneity seems to have only a small impact on the variability of GEP $(30,31)$. In endoscopic biopsy samples of colorectal cancer, the intratumor heterogeneity of GEP is smaller than intertumor heterogeneity (21). The findings of these studies are consistent with the current results. It is not clear how many biopsy samples from one patient are sufficient to assess the intratumor heterogeneity. In normal rectal epithelial specimens, two biopsy samples per person are recommended for microarray analysis based on the variation in gene expression data within a person (32). In cervical cancer, although the majority of genes are expressed relatively uniformly, a subset of genes can be expressed quite variably within a single patient. Genes which have a wide variation within a single patient require several biopsies, sometimes $>10$ biopsies, based on a statistical analysis. However, the optimum number of biopsies cannot be chosen based on statistical reasoning alone, because in the clinical practice, the feasibility of taking many biopsies from one patient is a restrictive factor (33). 
The question remains as to whether an endoscopic biopsy ESCC sample reflects the characteristics of the whole tumor. In breast cancer, by comparing GEP of tissue samples with the same cases of FNAB samples, the differences are looked closer (34). Komori et al reported that an endoscopic biopsy sample of colorectal cancer might give an accurate picture of the GEP in the whole tumor (21). In this study, although biopsy samples and resection samples were taken from different patients, $\sim 65 \%$ of the commonly up-regulated genes and $85 \%$ of the commonly down-regulated genes were overlapped. This result indicates that the GEP of endoscopic biopsy samples of ESCC may potentially represent the GEP of whole tumors.

In summary, comprehensive GEP using biopsy ESCC specimens is feasible and has the potential to represent the biological properties of ESCC. Further studies with comprehensive GEP using biopsy samples would provide a novel prediction system of neoadjuvant chemotherapy or chemoradiotherapy for ESCC.

\section{Acknowledgements}

We would like to thank Ms. Masayo Yamauchi for her valuable technical assistance. This study was partly supported by the Yasuda Medical Research Foundation.

\section{References}

1. Urschel JD and Vasan H: A meta-analysis of randomized controlled trials that compared neoadjuvant chemoradiation and surgery to surgery alone for resectable esophageal cancer. Am J Surg 185: 538-543, 2003.

2. Medical Research Council Oesophageal Cancer Working Group: Surgical resection with or without preoperative chemotherapy in oesophageal cancer: a randomised controlled trial. Lancet 359 . 1727-1733, 2002.

3. Ancona E, Ruol A, Santi S, Merigliano S, Sileni VC, Koussis H, Zaninotto G, Bonavina L and Peracchia A: Only pathologic complete response to neoadjuvant chemotherapy improves significantly the long term survival of patients with resectable esophageal squamous cell carcinoma: final report of a randomized, controlled trial of preoperative chemotherapy versus surgery alone. Cancer 91: 2165-2174, 2001.

4. Law S, Fok M, Chow S, Chu KM and Wong J: Preoperative chemotherapy versus surgical therapy alone for squamous cell carcinoma of the esophagus: a prospective randomized trial. J Thorac Cardiovasc Surg 114: 210-217, 1997.

5. Shimada Y, Watanabe G, Yamasaki S, Maeda M, Kawabe A, Kaganoi JI, Itami A, Fukumoto M, Kanda Y and Imamura M: Histological response of cisplatin predicts patients' survival in oesophageal cancer and p53 protein accumulation in pretreatment biopsy is associated with cisplatin sensitivity. Eur J Cancer 36: 987-993, 2000.

6. Miyata H, Doki Y, Shiozaki H, Inoue M, Yano M, Fujiwara Y, Yamamoto H, Nishioka K, Kishi K and Monden M: CDC25B and p53 are independently implicated in radiation sensitivity for human esophageal cancers. Clin Cancer Res 6: 4859-4865, 2000 .

7. Langer R, Specht K, Becker K, Ewald P, Bekesch M, Sarbia M, Busch R, Feith M, Stein HJ, Siewert JR and Höfler H: Association of pretherapeutic expression of chemotherapy-related genes with response to neoadjuvant chemotherapy in Barrett carcinoma. Clin Cancer Res 11: 7462-7469, 2005.

8. Ponder BAJ: Cancer genetics. Nature 411: 336-341, 2001.

9. Ramaswamy $\mathrm{S}$ and Golub TR: DNA microarrays in clinical oncology: J Clin Oncol 20: 1932-1941, 2002.

10. Golub TR, Slonim DK, Tamayo P, Huard C, Gaasenbeek M, Mesirov JP, Coller H, Loh ML, Downing JR, Caligiuri MA, Bloomfield CD and Lander ES: Molecular classification of cancer: class discovery and class prediction by gene expression monitoring: Science 286: 531-537, 1999.
11. van't Veer LJ, Dai H, van de Vijver MJ, He YD, Hart AA, Mao M, Peterse HL, van der Kooy K, Marton MJ, Witteveen AT, Schreiber GJ, Kerkhoven RM, Roberts C, Linsley PS, Bernards R and Friend SH: Gene expression profiling predicts clinical outcome of breast cancer. Nature 415: 530-536, 2002.

12. Beer DG, Kardia SL, Huang CC, Giordano TJ, Levin AM, Misek DE, Lin L, Chen G, Gharib TG, Thomas DG, Lizyness ML, Kuick R, Hayasaka S, Taylor JM, Iannettoni MD, Orringer MB and Hanash S: Gene-expression profiles predict survival of patients with lung adenocarcinoma. Nat Med 8: 816-824, 2002.

13. Iizuka N, Oka M, Yamada-Okabe H, Nishida M, Maeda Y, Mori N, Takao T, Tamesa T, Tangoku A, Tabuchi H, Hamada K, Nakayama H, Ishitsuka H, Miyamoto T, Hirabayashi A, Uchimura S and Hamamoto Y: Oligonucleotide microarray for prediction of early intrahepatic recurrence of hepatocellular carcinoma after curative resection. Lancet 361: 923-929, 2003.

14 Motoori M, Takemasa I, Yano M, Saito S, Miyata H, Takiguchi S, Fujiwara Y, Yasuda T, Doki Y, Kurokawa Y, Ueno N, Oba S, Ishii S, Monden M and Kato K: Prediction of recurrence in advanced gastric cancer patients after curative resection by gene expression profiling. Int J Cancer 14: 963-968, 2005.

15. Kihara C, Tsunoda T, Tanaka T, Yamana H, Furukawa Y, Ono K, Kitahara O, Zembutsu H, Yanagawa R, Hirata K, Takagi T and Nakamura Y: Prediction of sensitivity of esophageal tumors to adjuvant chemotherapy by cDNA microarray analysis of geneexpression profiles. Cancer Res 61: 6474-6479, 2001.

16. Ishibashi Y, Hanyu N, Nakada K, Suzuki Y, Yamamoto T, Yanaga K, Ohkawa K, Hashimoto N, Nakajima T, Saito H, Matsushima M and Urashima M: Profiling gene expression ratios of paired cancerous and normal tissue predicts relapse of esophageal squamous cell carcinoma. Cancer Res 63: 5159-5164, 2003.

17. Tamoto E, Tada M, Murakawa K, Takada M, Shindo G, Teramoto K, Matsunaga A, Komuro K, Kanai M, Kawakami A, Fujiwara Y, Kobayashi N, Shirata K, Nishimura N, Okushiba S, Kondo S, Hamada J, Yoshiki T, Moriuchi T and Katoh H: Geneexpression profile changes correlated with tumor progression and lymph node metastasis in esophageal cancer. Clin Cancer Res 10: 3629-3638, 2004

18. Ayers M, Symmans WF, Stec J, Damokosh AI, Clark E, Hess K, Lecocke M, Metivier J, Booser D, Ibrahim N, Valero V, Royce M, Arun B, Whitman G, Ross J, Sneige N, Hortobagyi GN and Pusztai L: Gene expression profiles predict complete pathologic response to neoadjuvant paclitaxel and fluorouracil, doxorubicin, and cyclophosphamide chemotherapy in breast cancer. J Clin Oncol 22: 2284-2293, 2004.

19. Clarke PA, George ML, Easdale S, et al: Molecular pharmacology of cancer therapy in human colorectal cancer by gene expression profiling. Cancer Res 63: 6855-6863, 2003.

20. Luthra R, Wu TT, Luthra MG, Izzo J, Lopez-Alvarez E, Zhang L, Bailey J, Lee JH, Bresalier R, Rashid A, Swisher SG and Ajani JA: Gene expression profiling of localized esophageal carcinomas: association with pathologic response to preoperative chemoradiation. J Clin Oncol 24: 259-267, 2006.

21. Komori T, Takemasa I, Yamasaki M, Motoori M, Kato T, Kikkawa N, Kawaguchi N, Ikeda M, Yamamoto H, Sekimoto M, Matsubara K, Matsuura N and Monden M: Gene expression of colorectal cancer: preoperative genetic diagnosis using endoscopic biopsies. Int J Oncol 32: 367-375, 2008.

22. Ohashi K, Nemoto T, Nakamura K and Nemori R: Increased expression of matrix metalloproteinase 7 and 9 and membrane type 1-matrix metalloproteinase in esophageal squamous cell carcinomas. Cancer 88: 2201-2209, 2000.

23. Yamashita K, Upadhay S, Mimori K, Inoue H and Mori M: Clinical significance of secreted protein acidic and rich in cystein in esophageal carcinoma and its relation to carcinoma progression. Cancer 97: 2412-2419, 2003.

24. Orimo A, Gupta PB, Sgroi DC, Arenzana-Seisdedos F, Delaunay T, Naeem R, Carey VJ, Richardson AL and Weinberg RA: Stromal fibroblasts present in invasive human breast carcinomas promote tumor growth and angiogenesis through elevated SDF-1/CXCL12 secretion. Cell 121: 335-348, 2005.

25. Alaoui-Jamali MA, Dupre I and Qiang H: Prediction of drug sensitivity and drug resistance in cancer by transcriptional and proteomic profiling. Drug Resist Updat 7: 245-255, 2004.

26. Burdelya LG, Komarova EA, Hill JE, Browder T, Tararova ND, Mavrakis L, DiCorleto PE, Folkman J and Gudkov AV: Inhibition of $\mathrm{p} 53$ response in tumor stroma improves efficacy of anticancer treatment by increasing antiangiogenic effects of chemotherapy and radiotherapy in mice. Cancer Res 66: 9356-9361, 2006 
27. Hori H, Miyake S, Akiyama Y, Endo M and Yuasa Y: Clonal heterogeneity in human esophageal squamous cell carcinomas on DNA analysis. Jpn J Cancer Res 87: 923-929, 1996.

28. Kuwabara S, Ajioka Y, Watanabe H, Hitomi J, Nishikura K and Hatakeyama K: Heterogeneity of p53 mutational status in esophageal squamous cell carcinoma. Jpn J Cancer Res 89: 405-410, 1998

29. Trautmann K, Steudel C, Grossmann D, Aust D, Ehninger G, Miehlke S and Thiede C: Expression profiling of gastric cancer samples by oligonucleotide microarray analysis reveals low degree of intra-tumor variability. World J Gastroenterol 11: 5993-5996, 2005.

30. Shmulevich I, Hunt K, El-Naggar A, Taylor E, Ramdas L, Labordé P, Hess KR, Pollock R and Zhang W: Tumor specific gene expression profiles in human leiomyosarcoma: an evaluation of intratumor heterogeneity. Cancer 94: 2069-2075, 2002.

31. Francis P, Fernebro J, Edén P, Laurell A, Rydholm A Domanski HA, Breslin T, Hegardt C, Borg A and Nilbert M Intratumor versus intertumor heterogeneity in gene expression profiles of soft-tissue sarcomas. Genes Chromosomes Cancer 43: 302-308, 2005.
32. Pellis L, Franssen-van Hal NL, Burema $\mathbf{J}$ and Keijer J: The intraclass correlation coefficient applied for evaluation of data correction, labeling methods, and rectal biopsy sampling in DNA microarray experiments. Physiol Genomics 16: 99-106, 2003.

33. Bachtiary B, Boutros PC, Pintilie M, Shi W, Bastianutto C, Li JH, Schwock J, Zhang W, Penn LZ, Jurisica I, Fyles A and Liu FF: Gene expression profiling in cervical cancer: an exploration of intratumor heterogeneity. Clin Cancer Res 12: 5632-5640, 2006.

34. Assersohn L, Gangi L, Zhao Y, Dowsett M, Simon R, Powles TJ and Liu ET: The feasibility of using fine needle aspiration from primary breast cancers for cDNA microarray analyses. Clin Cancer Res 8: 794-801, 2002. 